\title{
PERAN KEPUASAN PELANGGAN DALAM MEMEDIASI PENGARUH KUALITAS LAYANAN TERHADAP LOYALITAS PELANGGAN
}

\author{
I Nengah Asta Gina Jaya Artha ${ }^{1}$ \\ Ni Ketut Seminari ${ }^{2}$ \\ ${ }^{1,2}$ Fakultas Ekonomi dan Bisnis Universitas Udayana (Unud), Bali,Indonesia \\ e-mail: artha688@gmail.com
}

\begin{abstract}
ABSTRAK
Keberhasilan suatu perusahaan jasa ditentukan oleh kemampuan perusahaan tersebut dalam membangun loyalitas pelanggan. Penelitian dilakukan di Bengkel Honda Auto Global Motor dengan menggunakan ukuran sampel sejumlah 130 orang dengan metode nonprobability berbentuk purposive sampling. Teknik analisis datayang digunakan dalam penelitian ini yaitu path analyis serta uji sobel. Hasil penelitian menunjukkan bahwa kualitas layanan berpengaruh positif dan signifikan terhadap kepuasan pelanggan, begitupun terhadap loyalitas pelanggan. Selanjutnyakepuasan pelanggan berpengaruh positif dan signifikan terhadap loyalitas pelanggan. Selain itu kepuasan pelanggan secara simultanmemediasi pengaruh kualitas layanan terhadap loyalitas pelanggan. Hasil ini menggambarkan bahwa lingkungan pemasaran yang bersifat dinamis, sehingga untuk menjaga loyalitas pelanggan perusahaan diharapkan mampu menciptakan kualitas layanan yang sesuai dengan apa yang diharapkan para pelanggan sehingga timbul kepuasan.

Kata kunci : kualitas layanan, kepuasan pelanggan, loyalitas pelanggan
\end{abstract}

\begin{abstract}
The success of a service company is determined by the company's ability to build customer loyalty.The research was conducted at Honda Auto Global Motor Workshop using a sample size of 130 people with a non-probability form of method in thepurposive sampling. Data analysis techniques used in this study are path analyis and sobel test. The results showed that service quality has a positive and significant effect on customer satisfaction, as well as on customer loyalty. NextCustomer satisfaction has a positive and significant effect on customer loyalty. Besides that, customer satisfaction is simultaneouslymediate the influence of service quality on customer loyalty. These results illustrate that the marketing environment is dynamic, so as to maintain customer loyalty, the company is expected to be able to create quality services that are in line with what is expected by customers so that satisfaction arises.
\end{abstract}

Keywords : service quality, customer satisfaction, customer loyalty. 


\section{PENDAHULUAN}

Perkembangan industri otomotif di Indonesia sangat cepat dan cenderung meningkat tiap tahunnya, seiring dengan kebutuhan dan permintaan masyarakat akan sarana transportasi yang memadai. Keberhasilan suatu perusahaan jasa ditentukan oleh kemampuan perusahaan tersebut dalam membangun loyalitas pelanggan. Menurut Partua Pramana (2014) loyalitas pelanggan merupakan akibat dari suatu percobaan awal sebuah produk atau jasa yang diperkuat melalui kepuasan sehingga akan mengarah pada pembelian ulang. Sehingga loyalitas pelanggan sangat penting peranannya bagi perusahaan yang menjaga keberlangsungan usahanya (Purnomo dan Levina, 2011).

Salah satu faktor yang dapat menentukan dalam pemasaran yakni kepuasan pelanggan itu sendiri, jika pelanggan kecewa maka akan menjadi penghancur perusahaan. Maka dari itu kepuasan pelanggan dapat menjadi penyebab loyalitas pelanggan. Pernyataan ini relevan dengan penelitian lain yang dilakukan sebelumnya olehHafeez (2012); Sabir et al. (2013); Sauqi (2013); Wijayanto (2015); Fikri (2016); Minh (2016) dan Pamungkas (2016) yang menyatakan bahwa kepuasan pelanggan mempunyai pengaruh positif dan signifikan terhadap loyalitas pelanggan.

Kepuasan pelanggan memiliki hubungan erat dengan kualitas layanan, dimana pelanggan yang merasa puas terdorong untuk menjalin ikatan yang kuat dengan perusahaan. Menurut Parasuraman et al. (1988) kualitas layanan dikelompokkan ke dalam 5 dimensi yaitu tangibles, reliability, responsiveness, assurance dan empaty.Penelitian yang dilakukan oleh Natalisa (2007); Dewi 
I Nengah Asta Gina Jaya Artha, Peran Kepuasan Pelanggan ...

(2007); Nazamudin (2009); Utama (2010); Istianto (2011); Resihono (2011); Anggraeni (2012) dan Hygid Starini (2013) yang menjelaskan bahwa kualitas layanan yang terdiri dari bukti fisik, kehandalan, daya tanggap, jaminan, dan empati mempunyai pengaruh yang positif dan signifikan terhadap kepuasan pelanggan.

Meskipun terdapat hasil penelitian yang menunjukkan bahwa kualitas layanan berpengaruh positif dan signifikan terhadap kepuasan pelanggan, namun demikian terdapat hasil penelitian yang menyatakan bahwa kualitas layanan berpengaruh positif tetapi tidak signifikan terhadap kepuasan pelanggan. Penelitian tersebut adalah penelitian yang dilakukan oleh Yesenia dan Edward (2014) tentang "Pengaruh Kualitas Layanan dan Produk terhadap Kepuasan Pelanggan serta Loyalitas Pelanggan KFC di Tanggerang Selatan” yang menyatakan kualitas layanan berpengaruh positif terhadap kepuasan pelanggan namun tidak signifikan.

Penelitian lain yang menyatakan bahwa kualitas layanan secara langsung tidak berpengaruh positif dan signifikan terhadap loyalitas pelanggan. Penelitian tersebut adalah penelitian yang dilakukan oleh Ika Kusumasasti dkk. (2017) tentang "Pengaruh Kualitas Produk dan Layanan terhadap Loyalitas Pelanggan Coffee Shop" yang menyatakan bahwa kualitas layanan secara langsung tidak berpengaruh positif dan signifikan terhadap loyalitas pelanggan, namun berpengaruh positif dan signifikan terhadap loyalitas pelanggan melalui kepuasan pelanggan. Menurut Griffin (2005:11) semakin loyal seorang pelanggan, maka semakin besar laba yang diperoleh perusahaan. 
Berkembangnya usaha otomotif membuat usaha perbengkelan ikut terpacu. Bengkel Honda Auto Global Motor merupakan salah satu bengkel resmi khusus Honda yang berada di Jl. Nuansa Kori Taman Griya, Jimbaran, Badung. Bengkel Honda Auto Global Motor dalam menjalankan usahanya mampu meraih konsumen dalam jumlah yang cukup tinggi melalui berbagai inovasi dari kualitas layanan.

Tabel 1.

Jumlah Layanan Bengkel Auto Global Motor Bulan Januari -Oktober 2017

\begin{tabular}{lcc}
\hline Bulan & Jumlah Layanan & Perubahan (\%) \\
\hline Januari & 1.977 & \\
Februari & 1.896 & -4.1 \\
Maret & 1.989 & $(4.9)$ \\
April & 1.997 & $(0.4)$ \\
Mei & 2.004 & $(0.3)$ \\
Juni & 2.264 & $(13)$ \\
Juli & 1.875 & -17 \\
Agustus & 1.846 & -1.6 \\
September & 1.805 & -2.3 \\
Oktober & 1.756 & -2.8 \\
Jumlah & $\mathbf{1 9 . 4 0 9}$ & \\
\hline
\end{tabular}

Sumber: Bengkel Auto Global Motor Jimbaran, 2017

Tabel 1 menunjukkan bahwa total jumlah layanan Bengkel Auto Global Motor dari bulan Januari sampai bulan Oktober sejumlah 19.409 layanan. Berdasarkan data tersebut dapat dilihat jumlah layanan Bengkel Auto Global Motor cenderung mengalami peningkatan yang cukup signifikan sejak bulan Januari hingga bulan Juni. Total persentase peningkatan jumlah layanan dari bulan Januari hingga bulan Juni sebesar 15 persen, akan tetapi terjadi penurunan yang cukup drastis pada bulan Juli sebesar 17 persen dibanding bulan sebelumnya. Penurunan jumlah layanan terus berlanjut hingga bulan Oktober dengan total penurunan sebesar 24 persen. Hal ini terjadi karena kurangnya tenaga mekanik 
pada bulan Juli sampai bulan Oktober yang mengakibatkan layanan service menjadi tidak maksimal serta padatnya jumlah antrean yang menyebabkan kekecewaan dari beberapa pelanggan dan informasi waktu layanan service yang tidak sesuai dengan apa yang dijanjikan di awal pendaftaran.

Tujuan penelitian ini adalah untuk menjelaskan pengaruh kualitas layanan terhadap kepuasan pelanggan pada Bengkel Honda Auto Global Motor, untuk menjelaskan pengaruh kepuasan pelanggan terhadap loyalitas pelanggan pada Bengkel Honda Auto Global Motor, menjelaskan pengaruh kualitas layanan terhadap loyalitas pelanggan pada Bengkel Honda Auto Global Motor dan untuk menjelaskan peran kepuasan pelanggan dalam memediasi pengaruh kualitas layanan terhadap loyalitas pelanggan pada Bengkel Honda Auto Global Motor.

Penelitian ini tidak hanya berguna bagi para pembaca, melainkan untuk manajemen dari Bengkel Honda Auto Global Motor juga dapat menggunakan hasil penelitian ini guna untuk memajukan bisnisnya. Hasil dari penelitian ini diharapkan dapat menjadi referensi tambahan dan memperkuat hasil-hasil studi yang berhubungan dengan kualitas layanan terhadap kepuasan dan loyalitas pelanggan. Berdasarkan aspek praktis, penelitian ini diharapkan dapat menjadi pertimbangan bagi perusahaan dalam mengembangkan kebijaksanaan pihak bengkel terutama yang berhubungan dengan layanan dan kinerja karyawan atau mekanik terhadap pelanggan. Serta dapat menambah wawasan dan pemahaman bagi penulis sendiri.

Kerangka konseptual yang diajukan sebagai dasar penentu hipotesis ditunjukan pada Gambar 1 sebagai berikut. 


\section{Gambar 1. Kerangka Konseptual Penelitian}

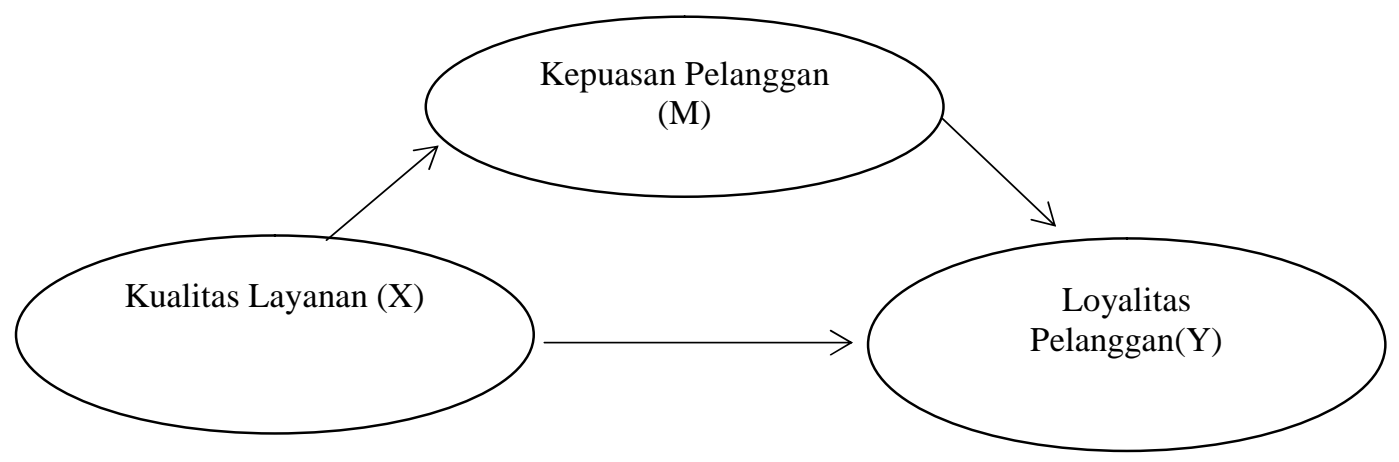

Kualitas layanan merupakan salah satu elemen penting yang menjadi pertimbangan bagi pelanggan dalam melakukan pembelian suatu produk atau jasa. Kualitas layanan merupakan tolak ukur dalam menentukan kepuasan konsumen atau tidaknya seorang pengguna jasa, karena melalui kualitas layanan akan dapat menilai kinerja dan merasakan puas atau tidaknya konsumen dengan layanan yang diberikan oleh penyedia jasa. Hubungan kualitas layanan dengan kepuasan pelanggan diperkuat dalam jurnal penelitian yang telah dilakukan oleh Farizal (2013) yang berjudul "Pengaruh Kualitas Layanan terhadap Kepuasan Konsumen Tiket pada PT. Artha Bangunan Cemerlang Tour And Travel”. Hasil penelitian menunjukkan bahwa kualitas layanan memiliki pengaruh yang positif dan signifikan terhadap kepuasan konsumen.

Penelitian yang dilakukan Simon (2016) yang berjudul "Pengaruh Kualitas Layanan Terhadap Kepuasan Pelanggan Pada Surya Nalendra Sejahtera Tours \& Travel". Hasil penelitian menunjukkan bahwa kualitas layanan berpengaruh secara positif dan signifikan terhadap kepuasan pelanggan. Kemudian penelitian yang dilakukan Shoki et al. (2012) menunjukkan hasil bahwa terdapat pengaruh yang positif dan signifikan antara kualitas layanan terhadap kepuasan pelanggan. 
I Nengah Asta Gina Jaya Artha, Peran Kepuasan Pelanggan ...

Menurut Zeithaml (2013) bahwa layanan merupakan hasil penilaian pelanggan secara menyeluruh. Apabila penilaian yang dihasilkan merupakan penilaian yang positif, maka kualitas layanan ini akan berdampak pada kepuasan pelanggan. Berdasarkan uraian diatas maka dapat dirumuskan hipotesis pertama yang akan diuji sebagai berikut:

$\mathrm{H}_{1}$ :Kualitas layanan berpengaruh positif dan signifikan terhadap kepuasan pelanggan

Kepuasan adalah ungkapan perasaan senang atau kecewa seseorang yang timbul setelah membandingkan kinerja yang diharapkan dengan kenyataan yang diperoleh (Kotler dan Keller, 2009:139). Dari definisi diatas dapat diketahui bahwa kepuasan pelanggan tidak lepas dari harapan pelanggan sehingga pelanggan memiliki peran yang cukup besar dalam menentukan seberapa besar layanan yang diberikan baik atau tidak.

Menurut Hurryati (2010) "pelanggan yang loyal mempunyai peran yang sangat penting bagi perusahaan, karena loyalitas seorang pelanggan bisa meningkatkan laba dan mempertahankan eksistensi sebuah perusahaan”. Menurut Griffin (2005) "konsep loyalitas pelanggan lebih banyak dikaitkan dengan perilaku daripada sikap, pembelian oleh seorang pelanggan bisa dikaitkan perilaku dan sikap adalah suatu perasaan yang diperlihatkan oleh seorang pelanggan setelah memakai produk atau jasa".Kemudian penelitain yang dilakukan oleh Chodzaza (2013); Peng (2015); Kuntari dkk. (2016) diperoleh hasil yaitu kualitas layanan berpengaruh positif dan signifikan terhadap loyalitas pelanggan. Berdasarkan teori dan uraian diatas maka dapat dirumuskan hipotesisnya sebagai berikut: 
$\mathrm{H}_{2}$ : Kualitas layanan berpengaruh positif dan signifikan terhadap loyalitas pelanggan

Kepuasan pelanggan dapat memengaruhi beberapa aspek penting salah satunya mengurangi elastisitas harga, meningkatnya loyalitas penlanggan, meningkatnya reputasi perusahaan, dan berkurangnya biaya transaksi masa depan (Tjiptono, 2011). Kepuasan terhadap loyalitas pelanggan menunjukkan bahwa kepuasan berpengaruh positif dan signifikan terhadap loyalitas pelanggan pada produk kosmetik hijau. Hal tersebut sesuai dengan penelitian yang dilakukan oleh Liu et al. (2012) menunjukkan hasil kepuasan pelanggan yang tinggi akan berdampak terhadap tingkat loyalitas. Demikian pula dengan penelitian yang dilakukan Nisa dkk. (2012) menunjukkan bahwa kepuasan pelanggan berpengaruh positif dan signifikan terhadap variabel terkait berupa loyalitas pelanggan. Berdasarkan teori dan uraian di atas maka dapat dirumuskan hipotesisnya sebagai berikut:

$\mathrm{H}_{3}$ : Kepuasan pelanggan berpengaruh positif dan signifikan terhadap loyalitas pelanggan.

Osman dan Sentosa (2013) telah menemukan hubungan mediasi diperkenalkan dalam model dimana kepuasan pelanggan sebagai mediator antara kualitas layanan dan loyalitas pelanggan. Kepuasan pelanggan secara parsial memediasi hubungan kualitas layanan dan loyalitas pelanggan pada pelanggan Malaysian Rural Tourism. Penelitian yang sama juga ditunjukkan oleh Mosahab et al. (2010) yang menunjukkan bahwa kepuasan pelanggan memainkan peran penting sebagai mediator pada efek kualitas layanan terhadap loyalitas pelanggan. 
I Nengah Asta Gina Jaya Artha, Peran Kepuasan Pelanggan ...

Demikian pula penelitian yang dilakukan oleh Malik (2012) yang menyatakan bahwa kepuasan pelanggan memiliki pengaruh yang positif dan signifikan dalam memediasi pengaruh kualitas layanan dengan loyalitas pelanggan. Hal ini sesuai dengan penelitian yang dilakukan oleh Sighn dan Thakur (2012). Berdasarkan uraian di atas, maka hipotesis yang diajukan adalah sebagai berikut:

$\mathrm{H}_{4}$ : Kepuasan pelanggan memiliki pengaruh positif dan signifikan dalam memediasi pengaruh antara kualitas layanan terhadap loyalitas pelanggan.

\section{METODE PENELITIAN}

Pendekatan yang digunakan adalah pendekatan kuantitatif dengan indikatorindikator pembentuk variabel yang mengacu pada beberapa sumber dan telah dimodifikasi agar sesuai dengan objek penelitian. Penelitian ini berfokus pada pelanggan Bengkel Honda Auto Global Motor sebagai subjek penelitian dengan meneliti objek penelitian yang meliputi kualitas layanan, kepuasan pelanggan dan loyalitas pelanggan. Variabel bebas dari penelitian ini adalah kualitas layanan (X), variabel mediasi yakni kepuasan pelanggan (M), serta variabel terikat yaitu loyalitas pelanggan (Y). Penelitian ini dilakukan di Bengkel Honda Auto Global Motor yang beralamat di JL. Nuansa Kori Taman Griya, Jimbaran, Badung. Bengkel ini dipilih karena banyaknya jumlah layanan service tiap bulannya yang mencapai 1.800-2.000 layanan dan tiap bulannya berfluktuasi. Selain itu terjadi penurunan jumlah service kendaraan yang cukup signifikan selama bulan Juli sampai bulan Oktober. 
Kualitas layanan merupakan salah satu elemen penting yang menjadi pertimbangan bagi pelanggan dalam melakukan pembelian suatu produk atau jasa. Pada penelitian ini menggunakan pendapat menurut Parasuraman et al. (1988:69) terdapat 5 dimensi kualitas layanan yang telah dimodifikasi dengan tempat penelitian yaitu: 1). Bukti Fisik (Tangibles); 2). Empati (Emphaty); 3). Keandalan (Reliability); 4). Daya tanggap (Responsiveness); 5). Jaminan (Assurance).

Kepuasan pelanggan adalah tingkat perasaan seseorang setelah membandingkan kinerja atau hasil yang dirasakan dibandingkan dengan harapan. Menurut pendapat Kotler \& Keller (2009:139), kepuasan merupakan fungsi dari kinerja yang dirasakan (perceived performance) dan harapan (expectations). Terdapat 4 indikator yang telah dimodifikasi dengan tempat penelitian untuk menganalisis kepuasan konsumen adalah menurut Fornell (1992) yaitu: 1). Kepuasan general atau keseluruhan (overall satisfaction) $\left(\mathrm{M}_{1}\right) ; 2$ ). Konfirmasi harapan (corfirmation of expectations) $\left(\mathrm{M}_{2}\right)$, yakni tingkat kesesuaian antara kinerja Bengkel Auto Global Motor dengan ekspektasi (harapan) pelanggan Bengkel Honda Auto Global Motor; 3). Perbandingan dengan situasi ideal (comparison to ideal) $\left(\mathrm{M}_{3}\right)$; 4). Melampaui batas harapan pelanggan $\left(\mathrm{M}_{4}\right)$.

Loyalitas secara umum dapat diartikan kesetiaan seseorang atas suatu produk, baik barang maupun jasa tertentu. Dalam penelitian ini menggunakan 4 indikator yang telah dimodifikasi dengan tempat penelitian untuk menganalisis tingkat loyalitas pengguna Bengkel Honda Auto Global Motor adalah menurut (Griffin, 2005): 1). Melakukan pembelian ulang (makes regular repeat purchases) $\left(\mathrm{Y}_{1}\right)$, yakni berlaku loyal dengan tetap melakukan perawatan di Bengkel Honda 
I Nengah Asta Gina Jaya Artha, Peran Kepuasan Pelanggan ...

Auto Global Motor 2). Membeli produk lain dari produsen yang sama (purchase across product and service line) $\left(\mathrm{Y}_{2}\right)$, yakni bukan hanya membeli satu jenis produk atau jasa tetapi juga membeli produk atau jasa tambahan yang disediakan oleh Bengkel Honda Auto Global Motor; 3). Merekomendasikan kepada orang lain (refers other) $\left(\mathrm{Y}_{3}\right)$, yakni bersedia merekomendasikan tentang layanan yang diberikan oleh Bengkel Honda Auto Global Motor kepada orang lain; 4). Menunjukkan kekebalan dari daya tarik produk sejenis dari pesaing (demonstrates an immunity to the full of the competition) $\left(\mathrm{Y}_{4}\right)$, yakni tidak ada niat untuk berpindah ke perusahaan lain.

Metode pengumpulan data yang dilakukan pada penelitian ini adalah dengan observasi dan kuisoner. Observasi dilakukan langsung ke Bengkel Honda Auto Global Motor di Jimbaran, Badung.Pada penelitian ini, kuesioner akan langsung diantarkan kepada sasaran responden ke lokasi penelitian yakni di Bengkel Honda Auto Global Motor. Kuesioner yang disebar terdiri dari pertanyaan terbuka yaitu identitas diri responden dan pernyataan mengenai pengaruh kualitas layanan terhadap kepuasan dan dampaknya pada loyalitas pelanggan. Pernyataan dalam kuesioner akan diukur dengan menggunakan Skala Likert

Populasi penelitian ini yaitu orang yang pernah menggunakan layanan Bengkel Honda Auto Global Motor. Indikator yang digunakan penelitian ini berjumlah 23 buah, maka ukuran sampel berada pada rentang $115-230$ responden. Karena keterbatasan peneliti jumlah responden dibatasi hanya 130 responden. Teknik penentuan sampel yang digunakan pada penelitian ini adalah non probability sampling dengan metode purposive sampling, yaitu sampel 
ditentukan dengan pertimbangan tertentu. Dimana kriteria sampel dalam penelitian ini sebagai berikut: 1). Responden merupakan pemilik langsung kendaraan bermotor; 2). Jejang pendidikan minimal SMA/SMK sederajat. Pertimbangan ini digunakan dengan alasan seseorang dengan jenjang Pendidikan minimal SMA sederajat diperkirakan dapat memahami dan mengerti isi dari kuesioner; 3). Responden minimal pernah datang sebanyak dua kali dalam rentang waktu enam bulan terakhir.

Penelitian ini menggunakan uji instrumen terlebih dahulu kemudian dilakukan uji sobel. Analisis jalur merupakan teknik model analisis yang digunakan untuk menganalisis pola hubungan antar variabel dengan tujuan untuk mengetahui pengaruh langsung maupun tidak langsung seperangkat variabel bebas terhadap variabel terikat. Masing - masing hipotesis memiliki persamaan struktural yang berbeda sebagai berikut:

Substruktural 1 adalah $\mathrm{M}=\mathrm{p}_{1} \mathrm{X}+\mathrm{e}_{1}$

Substruktural 2 adalah $Y=p_{2} M+p_{3} X+e_{2}$

Keterangan:

$\mathrm{X} \quad=$ kualitas layanan

$\mathrm{M} \quad=$ kepuasan pelanggan

$\mathrm{Y}=$ loyalitas pelanggan

$\mathrm{P}_{1} \quad=$ koefisien regresi variabel kualitas layanan berpengaruh langsung terhadap kepuasan pelanggan

$\mathrm{P}_{2}=$ koefisien regresi variabel kepuasan pelanggan berpengaruh langsung terhadap loyalitas pelanggan

$\mathrm{P}_{3}=$ koefisien regresi variabel kualitas layanan berpengaruh langsung terhadap loyalitas pelanggan 
I Nengah Asta Gina Jaya Artha, Peran Kepuasan Pelanggan ...

\section{PEMBAHASAN}

Bengkel Honda Auto Global Motor merupakan salah satu bengkel resmi Honda, dari sekian banyak bengkel resmi Honda yang ada di kabupaten Badung, provinsi Bali. Bengkel Honda Auto Global Motor didirikan oleh bapak Nengah Taru. Beliau merintis usaha bengkel tersebut sejak tahun 2014 yang pada mulanya hanya bengkel Honda biasa, bapak Taru memang sejak muda menyukai bidang otomotif, terutama tentang sepeda motor. Bapak Taru mendirikan Bengkel Honda Auto Global Motor setelah usahanya dibidang warnet, salon dan spa, toko komputer dan hp berjalan lancar. Bengkel motor ini baru menjadi bengkel resmi Honda setelah beliau mengajukan izin kepada PT. Astra Internasional Tbk. Honda HSO wilayah Bali, untuk mendirikan bengkel resmi Honda (AHASS) di wilayah Badung. Pada tanggal 18 September 2017 izin tersebut turun dari PT. Astra kemudian bapak Taru merubah layout bengkel serta fasilitas yang sesuai dengan standar bengkel resmi Honda.

Dengan semakin bertambahnya konsumen yang menggunakan jasa bengkel Auto Global Motor, maka bapak Taru berupaya melakukan berbagai perbaikan pada bengkelnya antara lain perbaikan disegi bangunannya, sumber daya manusia, peralatan, dan segi manajemennya. Perbaikan dari segi bangunannya diantaranya dengan memisahkan tempat service kendaraan dengan ruang tunggu, menyediakan berbagai fasilitas yang ada di ruang tunggu antara lain menyediakan $\mathrm{TV}$, koran dan majalah, menyediakan minuman ringan yang dapat dibeli oleh para konsumen yang menunggu kendaraan saat service serta ruangan yang ber-AC. Gudang suku cadang diperluas sehingga akan lebih banyak menampung barang- 
barang dan lebih mudah melakukan pengelompokkan suku cadang sesuai dengan jenisnya agar mudah bila dicari, menata ruang bengkel dengan memberikan meja khusus bagi layanan pendaftaran konsumen sehingga membuat bengkel terlihat lebih teratur.

Sumber daya manusia yang ada di Bengkel Honda Auto Global Motor kualitasnya juga terus ditingkatkan melalui berbagai program pelatihan yang diadakan oleh pihak PT. Astra Internasional - Honda HSO wilayah Badung dan menambah karyawan dibagian mekanik. Selain itu perusahaan juga menyediakan fasilitas komputer agar lebih mudah dalam pengawasan serta layanan. Bengkel Honda Auto Global Motor terletak di Jl. Nuansa Kori Taman Griya, Jimbaran, Bali. Bengkel ini buka dari pukul 08.00 sampai dengan 20.00 WITA setiap hari dan melayani service segala sepeda motor merk Honda. Bengkel Honda Auto Global Motor memiliki 9 Bike Lift jadi untuk penanganan service menjadi lebih cepat, untuk biaya service motor jenis matic dikenai harga sebesar Rp 65.000, untuk motor bebek dikenai harga sebesar Rp 55.000 dan untuk motor Sport dikenai harga sebesar Rp 70.000. Pemberlakuan harga service motor tersebut merupakan kebijakan terbaru terhitung mulai akhir 2016 hingga saat ini.

Responden dalam penelitian ini didominasi oleh laki-laki yaitu sebanyak 64 persen, sementara sisanya yaitu sebanyak 36 persen berjenis kelamin perempuan. Hasil sebaran ini dapat berarti bahwa lebih banyak konsumen laki-laki yang menggunakan layanan Bengkel Honda Auto Global Motor dibanding dengan konsumen perempuan saat penyebaran kuesioner dilakukan. Berdasarkan kriteria umur yang ditentukan, responden dengan rentang umur 33 sampai 38 tahun 
I Nengah Asta Gina Jaya Artha, Peran Kepuasan Pelanggan ...

mendominasi sebaran kuesioner ini yaitu sebesar 28 persen. Hal tersebut menunjukkan bahwa mayoritas responden berada pada rentang usia bekerja. Responden dengan rentang umur 18 sampai 23 tahun adalah sebesar 12 persen, rentang umur 23-28 sebesar 19 persen, rentang 28 sampai 33 sebesar 24 persen, rentang umur 33 sampai 38 sebesar 28 persen, serta responden yang umurnya lebih dari 38 tahun sebesar 17 persen.

Berdasarkan klasifikasi pekerjaannya, jumlah responden yang berstatus pegawai negeri sipil mendominasi sebaran kuesioner ini, yaitu sebesar 37 persen. Sebesar 9 persen adalah pelajar atau mahasiswa, sebesar 29 persen adalah pegawai swasta, sebesar 18 persen adalah wiraswasta, serta lainnya sebesar 7 persen. Hasil sebaran ini menunjukkan bahwa mayoritas pelanggan Bengkel Honda Auto Global Motor telah berpenghasilan sehingga dapat membeli jasa layanan bengkel dengan uang sendiri sesuai dengan kriteria responden dalam penelitian ini.

Pertama dilakukan uji instrument terlebih dahulu untuk menentukan apakah instrument dapat digunakan dalam penelitian ini. Pertama dilakukan uji validitas untuk mengetahui apakah instrumen yang digunakan telah memenuhi syarat sebagai alalt untuk prediksi dan setelah itu dilakukan uji reliabilitas untuk mengetahui apakah instrumen yang digunakan reliabel dan untuk mengetahui konsitensi instrumen itu sendiri. Hasil pengukuran validitas masing-masing instrumen pada variabel disajikan dalam Tabel 2 sebagai berikut. 
Tabel 2.

Hasil Uji Validitas

\begin{tabular}{|c|c|c|c|}
\hline Variabel & Instrumen & earson Correlation & Keterangan \\
\hline \multirow{15}{*}{$\begin{array}{l}\text { Kualitas Layanan } \\
\text { (X) }\end{array}$} & X.1 & 0,444 & Valid \\
\hline & X.2 & 0,564 & Valid \\
\hline & X.3 & 0,565 & Valid \\
\hline & X.4 & 0,576 & Valid \\
\hline & $X .5$ & 0,603 & Valid \\
\hline & X.6 & 0,640 & Valid \\
\hline & $X .7$ & 0,643 & Valid \\
\hline & X.8 & 0,546 & Valid \\
\hline & X.9 & 0,600 & Valid \\
\hline & X.10 & 0,721 & Valid \\
\hline & X.11 & 0,660 & Valid \\
\hline & X.12 & 0,698 & Valid \\
\hline & X.13 & 0,736 & Valid \\
\hline & X.14 & 0,634 & Valid \\
\hline & X.15 & 0,537 & Valid \\
\hline \multirow{4}{*}{$\begin{array}{c}\text { Kepuasan pelanggan } \\
\text { (M) }\end{array}$} & M1.1 & 0,650 & Valid \\
\hline & M1.2 & 0,735 & Valid \\
\hline & M1.3 & 0,737 & Valid \\
\hline & M1.4 & 0,652 & Valid \\
\hline \multirow{4}{*}{$\begin{array}{l}\text { Loyalitas pelanggan } \\
\text { (Y) }\end{array}$} & Y1.1 & 0,798 & Valid \\
\hline & Y1.2 & 0,783 & Valid \\
\hline & Y1.3 & 0,823 & Valid \\
\hline & Y1.4 & 0,471 & Valid \\
\hline
\end{tabular}

Sumber:Data diolah, 2018

Hasil uji validitas instrumen penelitian disajikan pada Tabel 2 yang menunjukkan bahwa seluruh indikator dalam variabelmemiliki nilai Pearson Correlation yang lebih besar dari angka 0,30 sehingga seluruh indikator tersebut dikatakan telah memenuhi syarat validitas data.

Uji Reliabilitas bertujuan untuk mengukur konsistensi alat ukur yang digunakan. Hasil pengukuran reliabilitas masing-masing variabel disajikan dalam Tabel 3 sebagai berikut.

Tabel 3.

Hasil Uji Reliabilitas

\begin{tabular}{lcl}
\hline Variabel & Cronbadh's Alpha & Keterangan \\
\hline Kualitas Layanan $(\mathrm{X})$ & 0,882 & Reliabel \\
Kepuasan Pelanggan $(\mathrm{M})$ & 0,740 & Reliabel \\
Loyalitas Pelanggan $(\mathrm{Y})$ & 0,787 & Reliabel \\
\hline
\end{tabular}

Sumber: Data diolah, 2018 
Hasil uji reliabilitas instrumen pada penelitian ini disajikan pada Tabel 3yang menunjukkan bahwainstrumen penelitian memiliki koefisien cronbach's alpha yang lebih besar dari angka 0,60 sehingga pernyataan pada kuesioner dapat dikatakan reliabel dan indikator yang digunakan merupakan indikator yang konsisten.

Penelitian ini menggunakan Analisis Jalur (Path Analysis) sebagai metode penelitiannya. Metode ini merupakan perluasan dari metode regresi linear berganda untuk menguji hubungan kausalitas antar dua variabel atau lebih. Berikut penjelasan lebih rinci mengenai tahapan dalam pengujian analisis jalur:

Tabel 4.

Hasil Analisis Jalur Persamaan Regresi 1

\begin{tabular}{lccc}
\hline Model & R Square & $\begin{array}{c}\text { Standardized Coefficients } \\
\text { Beta }\end{array}$ & Sig. \\
\hline Kualitas Layanan & 0,213 & 0,461 & 0,000 \\
\hline
\end{tabular}

Sumber: Data diolah, 2018

Berdasarkan hasil analisis jalur substruktural 1 yang disajikan pada Tabel 4, maka persamaan strukturalnya adalah:

$$
\begin{aligned}
& M=\beta_{1} X+e_{1} \ldots . \\
& M=0,461 X+e_{1}
\end{aligned}
$$

Nilai $\beta_{1}$ adalah sebesar 0,461 memiliki arti kualitas layanan berpengaruh positif terhadap kepuasan pelanggan, dengan kata lain jika faktor kualitas layanan meningkat maka kepuasan pelanggan meningkat sebesar 0,461 . 
Tabel 5.

Hasil Analisis Jalur Persamaan Regresi 2

\begin{tabular}{cccc}
\hline Model & \multirow{2}{*}{ R Square } & $\begin{array}{c}\text { Standardized Coefficients } \\
\text { Beta }\end{array}$ & Sig. \\
\hline Kualitas Layanan & 0,411 & 0,539 & 0,000 \\
Kepuasan Pelanggan & & 0,178 & 0,022 \\
\hline
\end{tabular}

Sumber: Data diolah, 2018

Berdasarkan hasil analisis jalur substruktural 2 yang disajikan pada Tabel 5, maka persamaan strukturalnya adalah:

$$
\mathrm{Y}=\beta_{2} \mathrm{X}+\beta_{3} \mathrm{Y}_{1}+\mathrm{e}_{2}
$$

$$
\mathrm{Y}=0,539 \mathrm{X}+0,178 \mathrm{Y} 1+\mathrm{e}_{2}
$$

Tabel 6.

Pengaruh Langsung dan Pengaruh Tidak Langsung serta Pengaruh Total

\begin{tabular}{cccc}
\hline Pengaruh Variabel & $\begin{array}{c}\text { Pengaruh } \\
\text { Langsung }\end{array}$ & $\begin{array}{c}\text { Pengaruh Tidak } \\
\text { Langsung Melalui } \\
\text { Mediasi }\end{array}$ & Pengaruh Total \\
\hline $\mathrm{X} \rightarrow \mathrm{M}$ & 0,461 & - & 0,461 \\
$\mathrm{X} \rightarrow \mathrm{Y}$ & 0,539 & 0,082 & 0,621 \\
$\mathrm{M} \rightarrow \mathrm{Y}$ & 0,178 & - & 0,178 \\
\hline
\end{tabular}

Sumber: Data diolah, 2018

Pada penelitian ini, pengaruh langsung variabel independen yaitu kualitas layanan terhadap variabel dependen yaitu loyalitas pelanggan mendapatkan hasil yang signifikan, begitu juga dengan hasil pengaruh tidak langsung melalui variabel mediator yaitu kepuasan pelanggan mendapatkan hasil yang signifikan. Oleh karena baik pengaruh secara langsung dan tidak langsung (melalui mediasi) mendapatkan hasil yang signifikan, maka pada penelitian ini variabel kepuasan pelanggan berperan secara parsial dalam memediasi pengaruh antara variabel kualitas layanan dengan variabel loyalitas pelanggan. 
Tujuan pertama dari penelitian ini adalah untuk menguji pengaruh kualitas layanan terhadap kepuasan pelanggan. Pengujian menunjukan hasil bahwa nilai koefisien beta positif sebesar 0,461 dengan tingkat signifikansi sebesar 0,000 (kurang dari 0,05$)$ yang artinya $\mathrm{H}_{1}$ diterima. Hasil ini mengindikasikan bahwa variabel kualitas layanan berpengaruh positif serta signifikan terhadap kepuasan pelanggan. Hasil pengujian menunjukan bahwa semakin tinggi kualitas layanan Bengkel Honda Auto Global Motor maka semakin semakin tinggi pula kepuasan pelanggan mereka, begitupun sebaliknya jika kualitas layanan Bengkel Honda Auto Gobal Motor semakin rendah maka semakin rendah pula kepuasan pelanggan mereka.

Penelitian ini juga bertujuan untuk menguji pengaruh kualitas layanan terhadap loyalitas pelanggan. Pengujian menunjukan hasil bahwa nilai koefisien beta positif sebesar 0,539 dengan tingkat signifikansi sebesar 0,000 (kurang dari 0,05) yang artinya $\mathrm{H}_{2}$ diterima. Hasil pengujian menunjukan bahwa semakin tinggi kualitas layanan Bengkel Honda Auto Global Motor maka semakin semakin tinggi pula loyalitas pelanggan mereka, begitupun sebaliknya jika kualitas layanan Bengkel Honda Auto Global Motor semakin rendah maka semakin rendah pula loyalitas pelanggan mereka.

Penelitian ini juga bertujuan untuk menguji pengaruh kepuasan pelanggan terhadap loyalitas pelanggan. Pengujian menunjukan hasil bahwa nilai koefisien beta positif sebesar 0,178 dengan tingkat signifikansi sebesar 0,022 (kurang dari 0,05) yang artinya $\mathrm{H}_{3}$ diterima. Hasil pengujian menunjukan bahwa semakin tinggi kepuasan pelanggan Bengkel Honda Auto Global Motor maka semakin 
semakin tinggi pula loyalitas pelanggan mereka, begitupun sebaliknya jika kepuasan pelanggan Bengkel Honda Auto Global Motor semakin rendah maka semakin rendah pula loyalitas pelanggan mereka.

Tujuan terakhir penelitian adalah untuk menguji peran kepuasan pelanggan dalam memediasi pengaruh kualitas layanan terhadap loyalitas pelanggan. Hasil Hasil pengujian menunjukkan pengaruh tidak langsung kualitas layanan terhadap loyalitas pelanggan melalui kepuasan pelanggan menghasilkan nilai t hitung sebesar 6,8371 yang lebih besar dibanding dengan $\mathrm{t}$ tabel yaitu 1,98, sehingga $\mathrm{H}_{4}$ diterima. Hasil ini mengindikasikan bahwa variabel kepuasan pelanggan mampu memediasi pengaruh kualitas layanan terhadap loyalitas pelanggan pada Bengkel Honda Auto Global Motor.

Interpretasi dari hasil tersebut adalah kualitas layanan yang dirasakan pelanggan Bengkel Honda Auto Global Motor sesuai dengan kepuasan pelanggan yang diterima saat service motor di Bengkel Honda Auto Global Motor sehingga mereka menjadi loyal. Efek mediasi yang terjadi adalah mediasi parsial atau partial mediation karena pada penelitian ini pengaruh variabel independen yaitu kualitas layanan terhadap variabel dependen yaitu loyalitas pelanggan secara langsung mendapatkan hasil yang signifikan, begitu juga secara tidak langsung melalui variabel mediasi yakni kepuasan pelanggan. Hasil ini dapat menjelaskan bahwa loyalitas pelanggan Bengkel Honda Auto Global Motor akan baik tidak hanya dengan kualitas layanan yang baik saja namun diikuti dengan kepuasan pelanggan yang baik juga. Berdasarkan hasil tersebut, manajemen Bengkel Honda Auto Global Motor tidak hanya serta merta membentuk kualitas layanan yang 
positif melainkan harus memperhatikan kepuasan pelanggan dengan memberikan fasilitas dan layanan yang sesuai demi membentuk loyalitas pelanggan yang tinggi.

Implikasi penelitian disini berusaha menekankan pada manfaat nyata dari hasil penelitian untuk mendorong usaha jasa agar tetap mampu memaksimalkan kualitas layanan guna tetap menjaga pelanggan agar tetap puas dengan layanan secara keseluruhan sehingga loyalitas para pelanggan mampu dipertahankan. Kualitas layanan merupakan komponen yang mampu meningkatkan kepuasan pelanggan Bengkel Honda Auto Global Motor. Penting bagi perusahaan untuk tetap fokus menjaga dan meningkatkan kualitas layanan agar sesuai dengan harapan pelanggan sehingga dapat meminimalisir keluhan terhadap layanan bengkel. Hal ini dapat menjadi strategi perusahaan untuk dapat meningkatkan kepuasan pelanggan dan pada akhirnya akan mendorong timbulnya loyalitas yang positif dari pelanggan Bengkel Honda Auto Global Motor.

Kepuasan pelanggan adalah komponen yang memicu timbulnya loyalitas pelanggan itu sendiri. Terjaganya kepuasan pelanggan terhadap layanan yang diberikan Bengkel Honda Auto Global Motor akan mendorong timbulnya loyalitas dari para pelanggan untuk tetap menggunakan layanannya. Terpenuhinya harapan pelanggan akan menciptakan persepsi positif yang mendorong konsumen melakukan pembelian secara berulang (repurchase), sehingga layanan yang diberikan oleh Bengkel Honda Auto Global Motor akan tetap menjadi prioritas utama dibenak para pelanggan. 
Keterkaitan antara kualitas layanan, kepuasan pelanggan dan loyalitas pelanggan bisa dijadikan tolak ukur bagi para pelaku bisnis untuk melihat bagaimana perilaku konsumen di dalam memilih, menyeleksi dan akhirnya menggunakan barang dan jasa yang secara umum menggambarkan bagaimana kualitas layanan jasa yang terdiri dari bukti fisik, empati, keandalan, daya tanggap, dan jaminan dipandang oleh konsumen sebagai patokan untuk menggunakan sebuah jasa. Loyalitas pelanggan berawal dari bagaimana pelanggan menilai kualitas layanan bengkel yang diterimanya (persepsi) berdasarkan harapan yang telah terkonsep dalam pikirannya. Apabila kualitas layanan telah sesuai atau bahkan melebihi harapan tentunya akan menimbulkan kepuasan. Konsumen yang merasa puas dengan kualitas layanan Bengkel Honda Auto Global Motor yang mereka terima tentu akan cenderung menjadikan layanan bengkel tersebut sebagai prioritas dengan melakukan pembelian ulang (repurchase) bahkan merekomendasikannya kepada pihak lain yang dimana semua itu merupakan indikasi dari pelanggan yang benar-benar loyal.

Namun terdapat beberapa keterbatasan dalam penelitian yang dilakukan. Penelitian ini belum mengangkat semua faktor ekstrinsik yang berkaitan dengan dimensi kualitas layananseperti bukti fisik, empati, keandalan, daya tanggap, dan jaminan. Di samping itu penelitian ini hanya dilakukan pada titik waktu tertentu (cross section) yang bersifat periodik dimana lingkungan yang bersifat dinamis sehingga terus mengalami perubahan. Kemudian ruang lingkup penelitian yang hanya dilakukan Bengkel Honda Auto Global Motor Jimbaran, sehingga hasil dari 
penelitian ini tidak dapat digeneralisasi untuk konsumen yang berada diluar wilayah Bengkel Honda Auto Global Motor.

\section{SIMPULAN DAN SARAN}

Berdasarkan hasil pembahasan, dapat ditarik beberapa simpulan sebagai berikut: 1). Kualitas layanan berpengaruh positif signifikan terhadap kepuasan pelanggan. Hasil penelitian ini menunjukkan bahwa semakin baik kualitas layanan Bengkel Honda Auto Global Motor, maka semakin tinggi pula kepuasan para pelanggan. Begitupun sebaliknya jika semakin rendah kualitas layanan Bengkel Honda Auto Global Motor, maka semakin rendah pula kepuasan para pelanggan; 2). Kualitas layanan berpengaruh positif signifikan terhadap loyalitas pelanggan. Hasil penelitian ini menunjukkan bahwa semakin baik kualitas layanan Bengkel Honda Auto Global Motor, maka semakin tinggi pula loyalitas para pelanggan. Begitupun sebaliknya jika semakin rendah kualitas layanan Bengkel Honda Auto Global Motor, maka semakin rendah pula loyalitas para pelanggan; 3). Kepuasan pelanggan berpengaruh positif signifikan terhadap loyalitas pelanggan. Hasil penelitian ini menunjukkan bahwa semakin tinggi kepuasan pelanggan Bengkel Honda Auto Global Motor, maka semakin tinggi pula loyalitas para pelanggan. Begitupun sebaliknya jika semakin rendah kepuasan pelanggan Bengkel Honda Auto Global Motor, maka semakin rendah pula loyalitas para pelanggan; 4). Kepuasan pelanggan berpengaruh signifikan dalam memediasi pengaruh variabel kualitas layanan terhadap variabel loyalitas pelanggan. Hasil ini menunjukan bahwa kualitas layanan yang dirasakan pelanggan Bengkel Honda Auto Global Motor sesuai dengan kepuasan yang diperoleh pelanggan saat menggunakan 
layanan bengkel tersebut, sehingga timbul loyalitas yang tinggi. Efek mediasi yang terjadi adalah mediasi parsial atau partial mediation karena pada penelitian ini pengaruh kualitas layananterhadap loyalitas pelanggan secara langsung mendapatkan hasil yang signifikan, begitupun dengan pengaruhnya secara tidak langsung melalui variabel mediasi yaitu kepuasan pelanggan.

Berdasarkan hasil analisis dari simpulan, maka saran yang dapat diberikan kepada Bengkel Honda Auto Global Motor diharapkan untuk tetap mencermati keluhan pelanggan dan melibatkan pelanggan dalam proses service. Pelanggan dapat disuruh melihat langsung proses service yang sedang berlangsung agar memahami situasi yang benar-benar terjadi dan kerusakan apa saja yang perlu dibenahi. Ketika ada kerusakan, pelanggan dapat diberikan pemahaman mengenai sparepart yang akan diganti, sehingga dengan adanya perlibatan pelanggan dalam proses tersebut dapat meningkatkan penilaian pelanggan atas kualitas jasa.

Bengkel Honda Auto Global Motor diharapkan menjaga kestabilan waktu kerja service secara fleksibel, dimana tergantung dengan apa yang menjadi tingkat kerusakan motor yang akan diperbaiki baik itu service ringan maupun berat dengan catatan waktu layanan service standar dari AHM. Dengan menjaga tingkat waktu layanan atau bisa dikatakan jaminan mutu waktu, maka akan menimbulkan kepuasan dibenak pelanggan dan diharapkan untuk menyesuaikan harga dengan kualitas layanan yang diberikan, karena tingkat loyalitas pelanggan akan menurun jika harga tidak sesuai dengan kualitas layanan yang diberikan.

Penelitian selanjutnya hendaknya dapat mengembangkan penelitian ini dengan mengacu pada keterbatasan penelitian yang telah disampaikan sebelumnya 
serta memasukkan faktor-faktor lain yang dirasa turut mempengaruhi kepuasan pelanggan maupun memediasi pengaruh kualitas layanan terhadap loyalitas pelanggan. Faktor-faktor tersebut tentu saja harus desesuaikan dengan dinamika yang berkembang dalam dunia pemasaran dan fenomena yang terjadi di sekitar.

\section{DAFTAR RUJUKAN}

Anggraeni, Nur Latifah. (2012). Analisis Pengaruh Dimensi Kualitas Pelayanan Terhadap Kepuasan Nasabah Pada BCA Cabang Telogorejo Semarang. Dinamika Manajemen. Vol. 1 (4), hal.35-47.

Aryani, Dwi dan Febrina Rosinta. (2010). Pengaruuh Kualitas Layanan terhadap Kepuasan Pelanggan dalam Membentuk Loyalitas Pelanggan. Jurnal Ilmu Administrasi dan Organisasi. Vol. 17 (2), hal.114-126.

Bilika, F., Safari, M., Mansori, S., (2016). Service Quality and Customer Satisfaction in Mozambique Banking System. Journal of Marketing Management and Consumer Behavior. Vol. 1 (3), hal. 114-126.

Chodzaza, G. E., \& Gombachika, H. S. H. (2013). Service quality, customer satisfaction and loyalty among industrial customers of a public electricity utility in Malawi. International Journal of Energ y Sector Management. Vol. 7 (2), Hal. 269-282.

Farizal, Brian. (2013). Pengaruh Kualitas Pelayanan terhadap Kepuasan Konsumen Tiket pada PT. Artha Bangunan Cemerlang Tour And Travel. Jurnal Manajemen Bisnis Transportasi dan Logistik, 2 (7), hal: 89-101.

Fikri, Sirhan, Wahyu Wiyana, Agung Suwandaru. (2016). Pengaruh Kualitas Pelayanan Terhadap Kepuasan Dan Loyalitas Mahasiswa. Fakultas Ilmu Sosial dan Ilmu Politik Universitas Merdeka Malang. Vol. 3 (1), hal. 120234.

Fornell, C. (1992). A National Customer Satisfaction Barometer: The Swedish Experience. Journal of Marketing. Vol. 56 (2): 234-246.

Hafeez, Samraz. Bakhtiar, Muhammad. (2012). The Impact Of Service Quality, Customer Satisfaction, And Loyalty Programs On Customer's Loyalty: Evidence From Banking Sector Of Pakistan. International Journal of Bussiness and Social Science. Vol.3, No.16: 908-1112. 
Ika Kusumasasti, Andarwati dan Djumilah Hadiwidjojo. (2017). Pengaruh Kualitas Produk dan Layanan terhadap Loyalitas Pelanggan Coffee Shop. Jurnal Ekonomi Bisnis. Vol. 22 (2), hal. 123-129.

Istianto, John Hendra dan Maria Josephine Tyra. (2011). Analisis Pengaruh Kualitas Layanan Terhadap Kepuasan Pelanggan Rumah Makan Ketty Resto. Jurnal Ekonomi dan Informasi Akuntansi. Vol. 1(3), hal.275-293.

Kotler, Philip dan Keller, Kevin Lane., (2009). Manajemen Pemasaran. Indeks. Edisi 13 jilid 1. Jakarta: Erlangga.

Kuntari, B.D., Kumadji, S., Hidayat, K., (2016). Pengaruh Kualitas Pelayanan Terahadap Kepuasan dan Loyalitas Pelanggan (Survei Pada Pelanggan Bengkel PT Astra International Tbk - Daihatsu Malang). Jurnal Administrasi Bisnis. Vol. 36, hal.196-202.

Liu, Chun-Chu., Hsing-Chau Tseng., Li-min Chuang., Chien-Min Huang. (2012). A Study of the Impact of the e-CRM Perspective on Customer Satisfaction and Customer Loyalty-Exemplified by Bank Sinopac. Journal of Economics and Behavioral Studies. Vol. 4 (8), pp.467-476.

Lovelock, Christopher, Jochen Wirtz, \& Jacky Mussry. (2011). Pemasaran jasa. Edisi 7. Erlangga: Jakarta.

Malik, Prof. Dr. Muhammad Ehsan. (2012). Impact of Brand Image, Service Quality and Price on Customer Satisfaction in Pakistan Telecommunication Sector. International Journal of business and Social Science. Vol. 3 (23), pp.123-129.

Mardikawati, Woro dan Naili Farida. (2013). Pengaruh Nilai Pelanggan dan Kualitas Layanan terhadap Loyalitas Pelanggan Melalui Kepuasan Pelanggan pada Pelanggan Bus Efisiensi. Jurnal Administrasi Bisnis. Vol. 2 (1), hal. 64-75.

Minh, Ngo Vu dan Nguyen Huan Huu. (2016). The Relationship between Service Quality, Customer Satisfaction and Customer Loyalty: An Investigation in Vietnamese Retail Banking Sector. Journal of Competitiveness. Vol. 8 (2), Hal. 103-116.

Mohamad, Arnber Abrahem dan Alhamadani, Shiren Yasen Mohamad. (2011). Service Qualiti Perspektif and Customer Satisfation in Comercials Bank Work in Jordan. Middle Eastern Finance and Economic. Vol. 1 (4), pp:611720 . 
Mosahab, Mahamad, Ramayah. (2010). Service Quality, Customer Satisfaction, and Loyalty: A Test of Mediation. International Business Research. Vol. 3 (4), pp. 72-80.

Natalisa, Diah. (2007). Survey Kepuasaan Pelanggan Program Studi Manajemen Universitas Sriwijaya. Jurnal Manajemen dan BisnisSriwijaya. Vol. 5 (9), hal.86-96.

Nazamudin, Herry. (2009). Pengaruh Kualitas Pelayanan Dan Produk Terhadap Loyalitas Konsumen. Jurnal Ekonomi Bisnis. Vol. 13 (1), hal.59-67.

Nelloh, L. A., dan Liem, C. C. (2011). Analisis Switching Intetion Pengguna Jasa Layanan Rumah Kos di Siwalayan kerto: Perspektif Kualitas Pelayanan dan Kepuasan Pelanggan. Jurnal Manajemen Pemasaran. Surabaya: Universitas Pelita Harapan. Vol. 6 (1), hal.27-31.

Osman, Zahir dan Sentosa, Ilham. (2013). Mediating Effect of Customer Satisfaction on Service Quality and Customer Loyalty Relationship in Malaysian Rural Tour. International Journal of Economics Business and Management Studies. Vol. 2 (1), pp.25-37.

Pamungkas, Ginda, Dion Dewa Brata. (2016). Pengaruh Kualitas Pelayanan Terhadap Kepuasan Pelanggan Serta Dampaknya Terhadap Loyalitas Pelanggan Pada SPBU 34.151.37. Manajemen. Institut Teknologi dan Bisnis Kalbis. Vol. 3 (1): 245-265.

Parasuraman, A., Valerie A. Zeithaml, and Leonard L. Berry,. (1988)."SERVQUAL: A Multiple Item Scalefor measuring Consumer Perception of Service Quality.”Journal of Marketing. Vol. 64, pp:12-40.

Peng, L. S., \& Moghavvemi, S. (2015). The Dimension of Service Quality and Its Impact on Customer Satisfaction, Trust, and Loyalty: A Case of Malaysian Banks. Asian Journal of Business and Accounting. Vol. 8 (2): 1-20.

Poniman, B., dan Supriyono. (2010). Pengaruh Dimensi Kualitas Pelayanan Terhadap Kepuasan Pasien Rumah Sakit "Nurmala Suri" Kabupaten Sukoharjo. Jurnal Ilmu Manajemen, Surakarta: STIE. AUB. Vol. 8 (8), hal.1-14.

Resihono, Legowo Dwi. (2011). Analisis Pengaruh Kualitas Jasa Pelayanan Terhadap Tingkat Kepuasan Konsumen Pada Hotel Kususma Kartika Sari. Jurnal Politeknosains. Vol. 10 (1), hal.36-56.

Riduwan \& Kuncoro, Engkos Achmad. (2011). Cara Menggunakan dan Memaknai Analisis Jalur (Path Analysis). Bandung: Alfabeta. 
Roza, T. A., Lubis, A. R., dan Amri. (2012). Pengaruh Kualitas Pelayanan Terhadap Kepuasan Konsumen Pada the Auto Bridal Banda Aceh. Jurnal Ilmu Mnajemen, Banda Aceh: Universitas Syiah Kuala. Vol. 1 (1), hal.1-20.

Sabir, Raja Irfan. Irfan, Muhammad. Sarwar, Muhammad Arslan. Sarwar, Binesh. Akhtar Naeem. (2013). The Impact of Service Quality, Customer Satisfaction, and Loyalty Programs on Customer's Loyalty: An Evidence from Telecommunication Sector. Journal of Asian Business Strategy. Vol.3, No.11: 802-820.

Sauqi, Ahmad dan Handriyanto. (2013). Uji Pengaruh Kualitas Layanan terhadap Kepuasan dan Loyalitas Pelanggan TV Berbayar Indovision Cabang Jember. Relasi. Jurnal Ekonomi-Mandala Jember. Vol. 18 (3), hal. 47-67.

Sekaran, Uma. (2013). Research Methods for Business. Jakarta. Salemba Empat.

Shoki M., Fen H.S., dan Ismail K. (2012). Relationship Between Customers Perceived Values, Satisfaction And Loyality Of Mobirle Phone Users. Review of Integrative Business \& Economic Research. Vol. 1 (1) pp.126135.

Simon, Kevin. (2016). Pengaruh Kualitas Pelayanan Terhadap Kepuasan Pelanggan Pada Surya Nalendra Sejahtera Tours \& Travel. Jurnal Manajemen dan Star-up Bisnis. Vol. 1 (3), hal.382-387.

Suwardi. (2011). Menuju Kepuasan Pelanggan Melalui Penciptaan Kualitas Pelayanan. Jurnal Pengembangan Humaniora. Vol. 11 (1), hal.51-58.

Tjiptono, Fandy dan Gregorius Chandra. (2012). Pemasaran Strategik. Yogyakarta. ANDI.

Utama, Agung. (2010). Analisis Pengaruh Persepsi Kualitas Pelayanan Terhadap Kepuasan Pelanggan Rumah Sakit Umum Cakra Husada Klaten. Jurnal Opsi. Vol. 2 (1), hal.9-172.

Wijayanto, Kusuma. (2015). Pengaruh Kualitas Pelayanan Terhadap Kepuasan dan Loyalitas Nasabah Bank. Jurnal Ekonomi Manajemen Sumber Daya. Vol. 17 (1), hal.38-45.

Yesiana, dan Edward H Siregar. (2014). Pengaruh Kualitas Layanan dan Produk terhadap Kepuasan serta Loyalitas Pelanggan KFC di Tanggerang Selatan. Jurnal Manajemen dan Organisasi. Vol. 5 (3), hal.184-199.

Zeithaml, V.A., M.J. Bitner, D.D Gremler. (2013). Services Marketing: Integrating Customer Focus Across the Firm $6^{\text {th }}$ ed. Mc.Grew-Hill: Boston. 